\title{
Design Modeling and Simulation of Fuzzy Controlled Sve for Long Over Head Transmission Line
}

\author{
Sharad Chandra Rajpoot ${ }^{1}$, Prashant Singh Rajpoot ${ }^{2}$, Kishan Gupta ${ }^{3}$, \\ Rewati Raman Yadav \\ ${ }^{1}$ Assistant professor G.EC.J agdalpur, bastar, Chhattisgarh, India, \\ ${ }^{2}$ Lecturer L.C.I.T., Bilaspur, Chhattisgarh, India, \\ ${ }^{3}$ PG scholar, Dept of Electrical \& Electronics Engineering, Dr.C.V. Raman Institute \&science \& Technology \\ Bilaspur, Chhattisgarh, India, \\ ${ }^{4}$ Assistant professor G.EC.J agdalpur, bastar, Chhattisgarh, India,
}

\begin{abstract}
The basic control objectives of a power system are system voltage control, system frequency control, protection and economic operation. Reactive power control is a subset of overall system control and stability. A power system is said to be well designed if it gives a good quality of reliable supply. By good quality is said meant the voltage levels are maintained within the reasonable limits. If the voltage variation is more than a pre specified value, the performance of the equipment suffers and the life of most of the equipment is sacrificed. When power is supplied to a load through transmission line keeping sending end voltage constant, the load voltage undergoes variations depending upon the magnitude of the load. The higher the load greater is the voltage variation. The transmission line distributed parameters through out the line, on light loads or at no loads become predominant and consequently the line supplies charging VAR (generates reactive power). In order to maintain the terminal voltage at the load bus adequate, reactive reserves are needed. FACTS devices like SVC can supply or absorb the reactive power at receiving end bus or at load end bus in transmission system, which helps in achieving better economy in power transfer. The fuzzy control has emerged as one of the most active and fruitful areas for research in the applications of fuzzy set theory. Fuzzy control is based on fuzzy logic - a logical system which is much closer in sprit to human thinking and nature language than traditional logical system. The fuzzy logic controller (FLC) provides a means of converting a linguistic control strategy based on an expert knowledge into an automatic control strategy. Knowledge acquisition in FLC application plays an important role in determining the level of performance of a fuzzy control system. FLC based on the fuzzy model of a process is needed when higher accuracy and reliability are required. Only small efforts have been expended in applying fuzzy logic as a controller to damp out the small signal oscillations for the FACTS based stabilizers as closed-loop.
\end{abstract}

Index Terms: fuzzy logic controller (FLC), fuzzy logic, FACTS, Reactive power control, SVC, power system stability.

\section{Introduction}

The power system is an interconnection of generating units to load centers through high voltage electric transmission lines and in general is mechanically controlled. It can be divided into three subsystems: generation, transmission and distribution subsystems. Until recently all three subsystems were under supervision of one body within a certain geographical area providing power at regulated rates. In order to provide cheaper electricity the deregulation of power system, which includes separate generation, Transmission and distribution companies, is already being implemented. At the same time electric power demand continues to grow and also building of the new generating units and transmission circuits is becoming more difficult because of economic and environmental reasons. Therefore, power utilities are forced to rely on utilization of existing generating units and to load existing transmission lines close to their thermal limits. However, stability has to be maintained at all times. Hence, it is necessary to operate power system effectively, without reduction in the systems security and quality of supply, even in the case of contingency conditions. The contingency may be such as loss of transmission lines and/or generating units, which occur frequently, and will most probably occur at higher frequencies. So a new control strategies need to be implemented, to take care of such expected situations.

Flexible AC Transmission Systems (FACTS) technology is based on the use of power electronic controlled devices for allowing transmission circuits to be used to their maximum thermal capability. In particular the FACTS devices aim principally to control the three main parameters directly effecting AC power transmission namely voltage, phase angle, and impedance. High Voltage Direct Current (HVDC) transmission is parallel technology using power electronics and is not normally included as a FACTS technology. 
Fuzzy control is based on fuzzy logic - a logical system which is much closer in sprit to human thinking and nature language than traditional logical system. The fuzzy logic controller (FLC) provides a means of converting a linguistic control strategy based on an expert knowledge into an automatic control strategy. Knowledge acquisition in FLC application plays an important role in determining the level of performance of a fuzzy control system. FLC based on the fuzzy model of a process is needed when higher accuracy and reliability are required. Only small efforts have been expended in applying fuzzy logic as a controller to damp out the small signal oscillations for the FACTS based stabilizers as closed-loop.

\subsection{Motivatition And Objective}

In this thesis transmission line is simulated using line segments by keeping the sending end voltage constant. The receiving end voltage fluctuations were observed for different loads. In order to maintain the receiving voltage constant, shunt inductor and capacitor are added for different loading conditions. SVC is simulated by means of Fixed Capacitor and Thyristor Controlled Reactor (FC-TCR) which is placed at the receiving end. The firing angle control circuit is designed and the firing angles are varied for various loading conditions to make the receiving end voltage equal to sending end voltage.

Fuzzy logic controller is designed to achieve the firing angles for SVC such that it maintains a flat voltage profile. All the results thus obtained, were verified and were utilized in framing of fuzzy rule base in order to achieve better reactive power compensation for the Transmission line. Based on observed results for load voltage variations for different values of load resistance, inductance and capacitance a fuzzy controller is designed which controls the firing angle of SVC in order to automatically maintain the receiving end voltage constant.

\subsection{Overview}

\section{Facts Devices}

Power electronic devices have had a revolutionary impact on the electric power systems around the world. The availability and application of thyristors has resulted in a new breed of thyristor-based fast operating devices devised for control and switching operations. Flexible AC Transmission System (FACTS) devices are new comings, which have found a wide spread application in the power industry for active and reactive power control.

High Voltage Direct Current (HVDC) transmission is parallel technology using power electronics and is not normally included as a FACTS technology.

$>$ Constraints preventing use of full thermal capability on conventional AC circuits are

- Poor power sharing in parallel circuits under different network operating conditions.

- Transient, dynamic and voltage instability.

- Voltage control and associated reactive power flow problems.

- Fault level constraints.

$>$ Technologies available for improving circuit utilization

- Changes to network configuration.

- HVDC.

- FACTS.

$>$ Advantages of FACTS technology over other solutions to network reinforcement

- Has potential to control flow as required.

- Less environmental impact than most alternative techniques of transmission reinforcement.

- Cost is also less than other alternatives.

- Due to the invention of modern power electronic components such as Gate Turn Off (GTO) Thyristor, and Voltage Source Inverter (VSI) technology, new generation of FACTS devices are developed.

\subsection{Types of facts Controllers}

FACTS controllers can be broadly divided into four categories, which are

- Series controllers

- Shunt controllers

- Combined Series-Series Controllers

- Combined Series -Shunt controllers

1) Series controller:-

1. Static Synchronous Series Comparator (SSSC)

2. Inter line Power Flow Controller (IPFC)

3. Thyristor Controlled Series Capacitor (TCSC)

4. Thyristor Switched Series Capacitor (TSSC) 
5. Thyristor Controlled Series Reactor (TCSR)

6. Thyristor Switch Series Reactor (TSSR)

2) Shunt Controllers:-

1. Static Synchronous Compensator (STATCOM)

2. Static Synchronous Generator (SSG)

3. Battery Energy Storage System (BESS)

4. Super Conducting Magnetic Energy Storage (SMES)

5. Static VAR Compensator (SVC)

6. Thyristor Controlled Reactor (TCR)

7. Thyristor Switched Reactor (TSR)

8. Thyristor Switched Capacitor (TSC)

9. Static VAR Generator or Absorber

3) Combined shunt - series connected controllers

1. Unified Power Flow Controller (UPFC).

4) Combined series - series connected controllers

1. Inter Line Power Flow Controller (IPFC).

\subsection{Principles of the Series Controllers}

A series controller may be regarded as variable reactive or capacitive impedance whose value is adjusted to damp various oscillations that can take place in the system. This is achieved by injecting an appropriate voltage phasor in series with the line; this voltage phasor can be viewed as the voltage across impedance in series with the line.

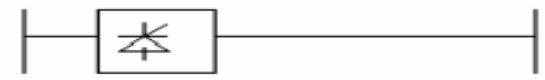

Figure 2.1: Series controller

Examples:

1. Static Series Synchronous Compensator (SSSC).

2. Thyristor Controlled Series Capacitor (TCSC).

\subsubsection{Static series synchronous compensator (SSSC)}

A static synchronous generator operated without an external electric energy source as a series compensator whose output voltage is in quadrature with and controllable independently, of the line current for the purpose of controlling the transmitted electric power. The SSSC may include transiently rated energy storage by additional temporary real power compensation, to increase or decrease momentarily the overall real voltage drop across the line.

\subsubsection{Thyristor Controlled Series Capacitor (TCSC)}

A capacitive reactive compensator which consists of a series capacitor bank by a thyristor controlled reactor in order to provide a smoothly variable series capacitive reactance.

\subsubsection{Principles of the Shunt Controllers}

Shunt controllers are similar to the series controllers with the difference being that they inject current into the system at the point where they are connected. Variable shunt impedance connected to a line causes a variable current flow by injecting a current into the system. If the injected current is in phase quadrature with the line voltage, the controller adjusts reactive power while if the current is not in phase quadrature, the controller adjusts real power.

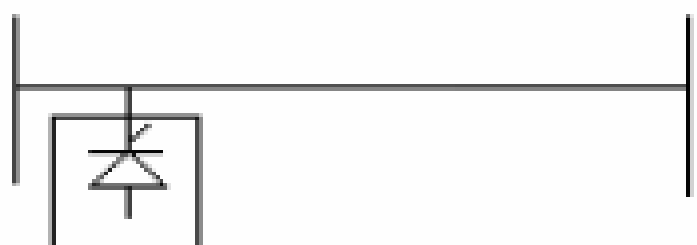

Figure: 2.2. Shunt controller 


\section{Examples:}

1. Static Synchronous Compensator (STATCOM)

2. Static Var Compensator (SVC)

They can be used as a good way to control the voltage in and around the point of connection by injecting active or reactive current into the system.

\subsubsection{Static Synchronous Compensator (STATCOM)}

This is a Static Synchronous Generator operated as a shunt connected static Var compensator whose capacitive or inductive output current can be controlled independent of the ac system voltage.

\subsubsection{Static Var Compensator (SVC)}

A shunt connected static Var generator or absorber whose output is adjusted to exchange capacitive or inductive current so as to maintain control specific parameters of the electrical power system.

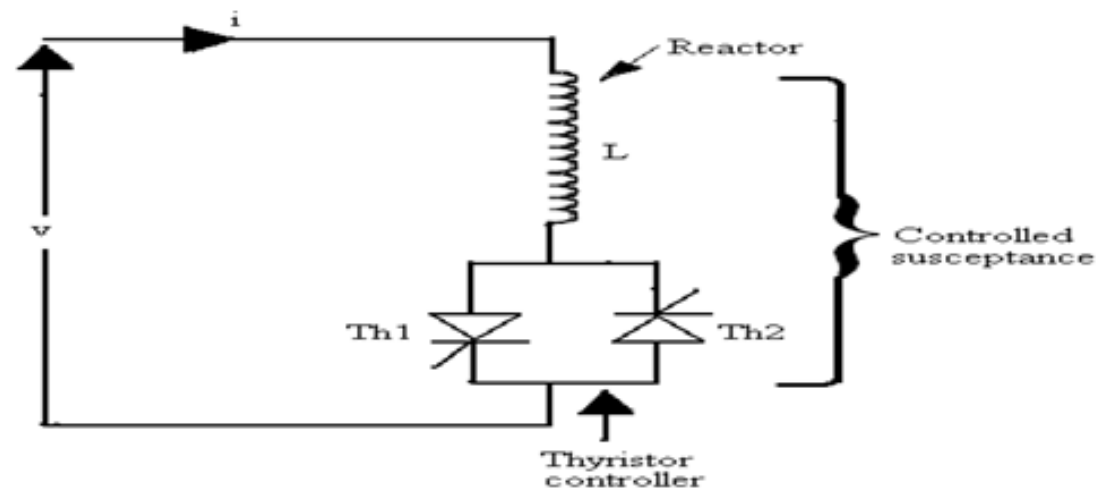

Fig. 2.3 Basic Thyristor Controlled Reactor

\subsubsection{Principles of the Combined Series-Series Controllers.}

A combined series-series controller may have two configurations. One Configuration consists of series controllers operating in a coordinated manner in a multi line transmission system. The other configuration provides independent reactive power control for each line of a multi line transmission system and, at the same time, facilitates real power transfer through the power link.

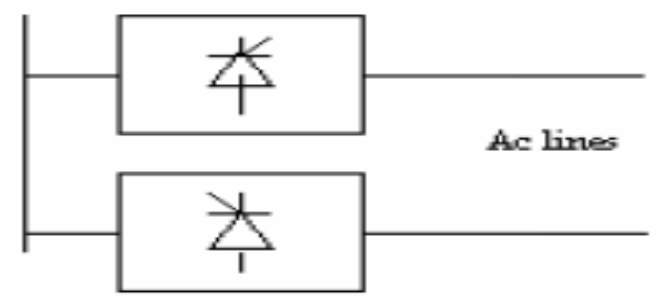

Figure 2.4: Series-series controller

Example: Interline power flow controllers (IPFC)

This helps in balancing both the real and reactive power flows on the lines.

\subsubsection{Unified Power Flow Controller (UPFC)}

A combination of static synchronous compensator (STATCOM) and a static series compensator (SSSC) which are coupled via a common dc link, allow bidirectional flow of real power between the series out put terminals of the SSSC and the shunt output terminals of the STATCOM, and are controlled to provide concurrent real and reactive series line compensation without an external electrical energy source. The UPFC, by means of angularly unconstrained series voltage injection, is able to control, concurrently, or selectively, the transmission line voltage, impedance, and angle or, alternatively, the real and reactive power flow in the line. The UPFC may also provide independently controllable shunt reactive compensation. 


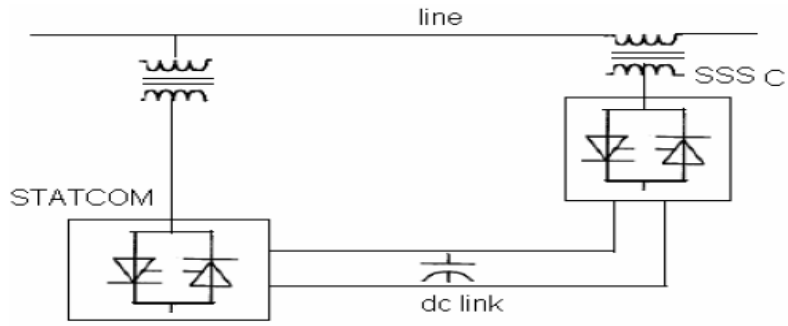

Figure 2.5: Unified Power Flow Controller (UPFC)

In UPFC fig.2.5, which combines a STATCOM and an SSSC, the active power for the series unit (SSSC) is obtained from the line itself via the shunt unit STATCOM the letter is also used for voltage control with control of its reactive power. This is a complete control for controlling active and reactive power control through the line, as well as line voltage control.

\subsubsection{Basic Operating Principle and Characteristics.}

The unified power flow controller (UPFC) was devised for the real-time control and dynamics compensation of ac transmission systems, providing multi-functional flexibility required to solve many of the problems facing the industry.

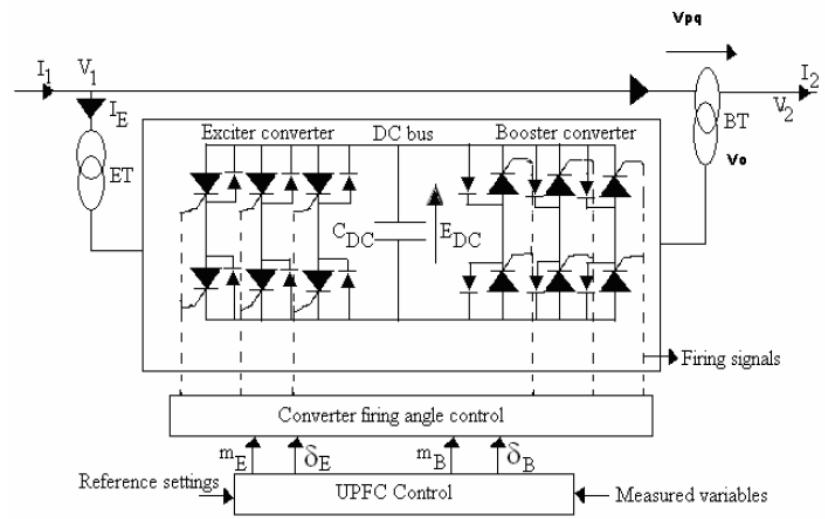

Fig 2.6 Implementation of the UPFC by two back-to-back voltage sourced converters.

\subsection{Introduction}

\section{Design And Modeling of Transmission Line}

An Electrical transmission line can be represented by a series combination of resistance, inductance and shunt combination of conductance and capacitance. these parameters are symbolized as R,L,G and C respectively, of these $\mathrm{R}$ and $\mathrm{G}$ are least important in the sense that they do not effect much the total equivalent impedance of the line and hence the transmission capacity. They are of course very much importance when transmission efficiency and economy are to be evaluated as they completely determine the real transmission line losses. The resistance of a conductor is given by

\section{$\mathbf{R}=$ power loss in conductor $/ \mathbf{I}^{2}$ ohms}

Where $\mathrm{R}$ is the effective resistance of the conductor and I the current flowing through the conductor. The effective resistance is equal to the D.C resistance of the conductor only if the current is uniformly distributed throughout the section of the conductor. Difference in the D.C resistance and effective resistance to frequencies less than $50 \mathrm{~Hz}$ is less than 1 percent for copper conductors of section less than 350,000 circular mils. The loss on the overhead transmission line is due to

1. Ohmic loss in the power conductors

2. corona loss

3. leakage at the insulators which support the lines at the towers

The performance of lines is meant the determination of efficiency and regulation of lines

$\%$ efficiency $=$ power delivered at the receiving end /power sent from the sending end $* 100$

3.2 
Regulation of a line is defined as the change in the receiving end voltage, expressed in percent of full load voltage, from no load to full load, keeping the sending end voltage and frequency constant. Expressed mathematically,

$$
\% \text { regulation }=\left(V^{!} \mathbf{r}-\mathrm{Vr}\right) / \mathrm{Vr} * 100
$$

Where $\mathrm{V} ! \mathbf{r}$ is the receiving end under no load condition and $\mathrm{Vr}$ the receiving end voltage under full load condition .it is to be noted here that $V^{\prime} r$ and $\mathrm{Vr}$ are the magnitudes of voltage.

\subsection{Representation of transmission lines}

A transmission line is a set of conductors being run from one place to another supported on transmission towers. Such lines, therefore, have foure distributed parameters, series resistance and inductance and shunt capacitance and conductance.it is to be noted that the electrical power is being transmitted over the overhead lines at approximately the speed of light .in order to get one full wave variation of voltage or current on the line, the length of the line for $50 \mathrm{~Hz}$ supply will be given by

$$
\mathbf{f} * \square=\mathbf{v}
$$

where $\mathrm{f}$ is the frequency of supply, $\lambda$ is wavelength i.e the length of the in this case and $\mathrm{v}$ the velocity of the wave i.e the velocity of light

$$
\square=\mathbf{v} / \mathbf{f}=\mathbf{6 0 0 0} \mathrm{Km}
$$

This means that if the length of the line is $6000 \mathrm{Km}$ the voltage or current wave at the two ends of the line Transmission lines have been classified as lang and medium and short lines depending on the length of the lines. These are

\section{Upto 80km---short line}

80 to $160 \mathrm{~km}$-----medium line

Above 160km----long transmission line

\subsection{Surge Impedance}

The surge impedance of a typical overhead line is $400 \Omega$. The transmission network is so selected as to satisfy these conditions. The transmission network studied is shown in fig4.1.Surge impedance:The surge impedance of a line is calculated from the formula

$$
\text { Zs }=\text { Sqrt }(\mathbf{L} / \mathbf{C})
$$

Where Zs=surge impedance

$\mathrm{L}=$ line inductance

$\mathrm{C}=$ line capacitance

For the selected network $\mathrm{L}=14.8 \mathrm{mh}$ and $\mathrm{C}=20 \mu \mathrm{f}$ Substituting these values in the formula for $\mathrm{Zs}$ we get

$$
\mathrm{Zs}=\operatorname{sqrt}(\mathrm{L} / \mathrm{C})=368.2 \Omega
$$

This value is nearly equal to the value ought to be for an overhead line. Hence from the above two cases it is clear that the selected network is near to a practical long transmission line. The transmission line is shown in fig 3.1 .

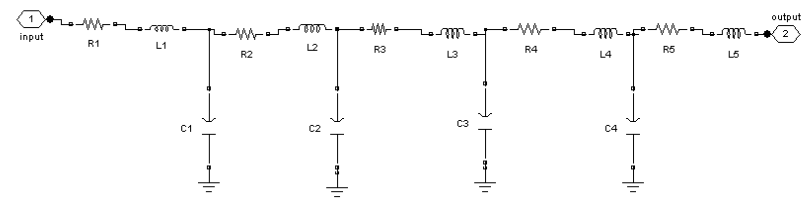

Fig 3.1 Transmission line test system

\subsection{Ferranti-effect}

When a long line is operating under no load or light load condition, the receiving end voltage is greater than sending end voltage, this is known as Ferranti-effect. Ferranti-effect can be given by approximating the distributed parameters of the line by lumped impedance shown in figure below. The charging current produces drop in the reactance of the line which is in phase opposition to the receiving end voltage and hence the sending end voltage becomes smaller than the receiving end voltage. 


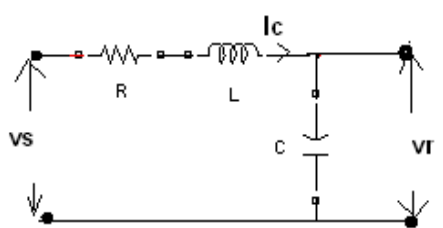

Fig 3.2(a) Line representation under no load

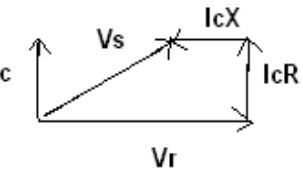

Fig 3.2(b) phasor diagram

\subsection{Flexible AC transmission systems Methods of transmission Line compensation 3.5.1 Compensation methods}

The model used for assessing the effects of compensation methods on transmission capability is shown in Fig. 1 (without any compensationPower is being exported along the line from the sending end bus bar (left hand side) towards the receiving end bus bar (right hand side) as shown by the direction of the line current, 1 . In the analysis of transmission networks for design and operational purposes it is often necessary to include a more rigorous line representation particularly where longer transmission distances are involved.. Fig. 2 shows the voltage variation at the receiving end of a transmission line assuming a constant lagging power factor load and distributed network parameters. Three cases are illustrated: (a) with no compensation, (6) with distributed compensation to provide a flat profile and $(c)$ with limited capacitive compensation at the receiving end. Under light load conditions the receiving end voltage can rise higher than the sending end voltage due to the effects of the line capacitance (Ferranti effect).

\subsubsection{Uncompensated line}

Referring to the simplified model of the uncompensated system of Fig. $3.3 \mathrm{a} \& \mathrm{~b}$ the voltage at the midpoint of the line is taken to be $V_{M}$, the real power $P$, exported along the line is given as:

$P=\frac{V^{2}}{x} \sin \delta$

3.7
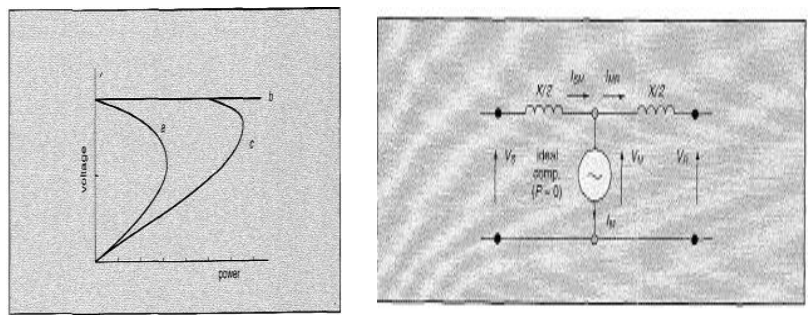

Fig 3.3(a) Simple power system model

Fig 3.3(b) Voltage variation at a receiving end bus bar as afunction of power Flow
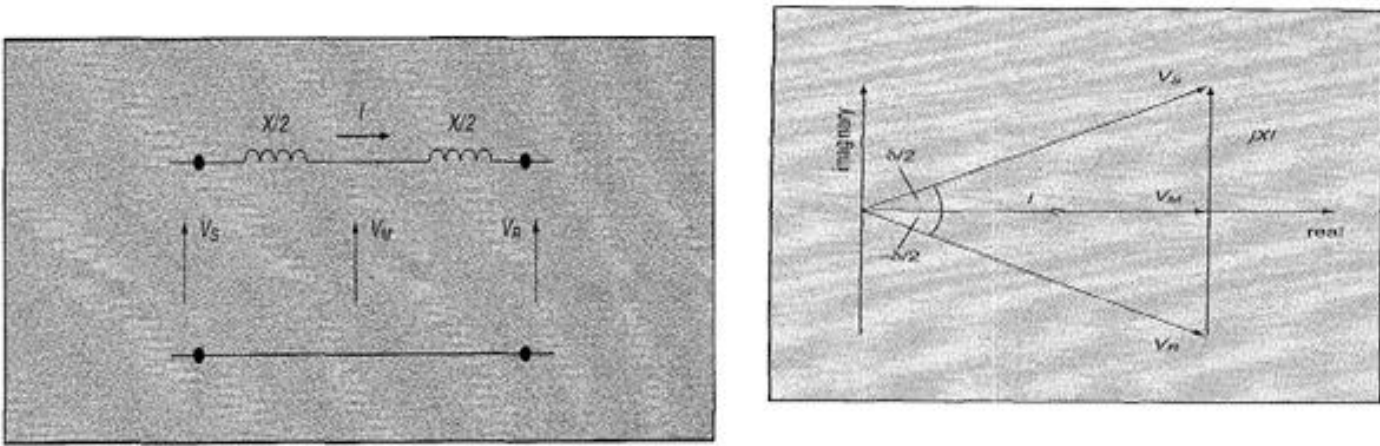

Fig 3.4 Phasor diagram for simple model shown in Fig. 3.3

Assuming that $\mathrm{I} V s \mathrm{I}=\mathrm{I} \mathrm{V}_{\mathrm{R}} \mathrm{I}=\mathrm{I}$ VI. From the phasor diagram of Fig. 3.4, we can see that:

$\sin \frac{\delta}{2}=\frac{I X}{2 V} \rightarrow \prime=2 \frac{V}{X} \sin \frac{\delta}{2}$

3.8 
The line absorbs reactive power, $\mathrm{Q}$, as a function of the line current:

$$
Q=I^{2} X=\frac{4 V^{2}}{X} \sin ^{2} \frac{\delta}{2}=\frac{2 V^{2}}{X} 2 \sin ^{2} \frac{\delta}{2}
$$

This can be expressed as:

$$
Q=\frac{2 V^{2}}{X}(1-\cos \delta)
$$

The variation in transmitted real power (eqn. 1) and absorbed reactive power

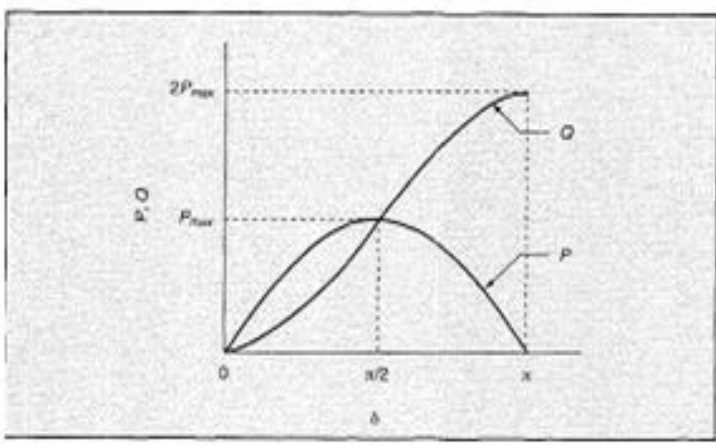

Fig 3.5 Power transmission characteristic for simple 3.3mid-point shunt compensator eqn. 4) is shown in Fig. 3.5 as a function of the angle, 6, between the bus bar voltages.

\subsubsection{Shunt compensation}

We see in Fig. 3 that the voltage profile of the uncompensated transmission line (i.e. how the voltage magnitude varies along the line length) is a maximum at the line ends, $\mathrm{V}$, and a minimum at the mid point, $\mathrm{V}_{\mathrm{M}}$, Fig. 5 shows the arrangement of the ideal mid-point shunt compensator which maintains a voltage, equal to the bus bar voltage such that $\left.1 \mathrm{Vsl}=1 \mathrm{~V}_{\mathrm{R}}\right]=\mathrm{I} \mathrm{V}_{\mathrm{M}} \mathrm{I}=\mathrm{IVI}$. It can be seen that the compensator does not consume real power since the compensator voltage $\mathrm{V}_{\mathrm{M}}$ and its current $\mathrm{I}_{\mathrm{M}}$ are in quadrature. Clearly, the power, $P$, transferred from $S$ to the mid-point is equal to the power transferred from the mid-point to $R$, and is given by:

$$
P=\frac{V^{2} \sin \frac{\delta}{2}}{\frac{x}{2}}=2 \frac{v^{2}}{x} \sin \frac{\delta}{2}
$$

The reactive power generated by the compensator, $Q$, is given generally by $Q_{p}=I_{M} V_{M}=I_{M} V$. From the phasor diagram (Fig. 3.7), $I$, can be expressed in terms of $I_{S M}$

And $\sigma$ :

$\sin \frac{\delta}{4}=\frac{I_{M}}{2 I_{S M}} \rightarrow I_{M}=2 I_{S M} \sin \frac{\delta}{4}$

Adapting eqn. 2 to replace, we can express $Q P$ as:

$$
Q_{P}=I_{M} V_{M}=2 I_{S M} \sin \frac{\delta}{4} V=2 \frac{2 V \sin \frac{\delta}{4}}{\frac{x}{2}} \sin \frac{\delta}{4} V
$$

This can be arranged as

$Q_{p}=\frac{8 V^{2}}{X} \sin ^{2} \frac{\delta}{4}=\frac{4 V^{2}}{X} 2 \sin ^{2} \frac{\delta}{4}=\frac{4 V^{2}}{X}\left(1-\cos \frac{\delta}{2}\right)$

The real power flowing through the line (eqn. 5), and the reactive power generate Fig 3.7 Fig 3.7 Phasor diagram for shunt-compensated line shown in Fig 3.6

\subsubsection{Series capacitance compensation}

This method does not improve the voltage profile but makes the line appear much shorter, electrically, than is the case. Denoting the line reactance as Fig 3.8 Power transmission characteristic for shunt compensated line Shown in Fig3.6

$\mathrm{X}_{\mathrm{L}}$, and the capacitance reactance as\&, the overall line reactance, $\mathrm{X}_{\mathrm{C}}$, becomes $\mathrm{X}_{\mathrm{C}}-\mathrm{X}_{\mathrm{L}}$ or, alternatively, $X=X_{L}(l$ -s), where $S$ is the degree of compensation given by: 


$$
s=\frac{x_{C}}{x_{L}} \quad 0 \leq s \leq 1
$$

The real power, $P$, can now be expresses as,.

$$
P=\frac{V^{2}}{X} \sin \delta=\frac{V^{2}}{X_{L}(1-s)} \sin \delta
$$

The reactive power supplied by the series capacitor is given by $Q_{C}=I^{2} X_{C}$. From the phasor diagram of Fig. 3.9, the following expression can be derived:

$$
\sin \frac{\delta}{2}=\frac{I_{s} \frac{x_{L}}{2}-t_{s} \frac{x_{c}}{2}}{V}
$$

This can be rearranged as:

$$
I_{s}=\frac{2 v \sin \frac{\delta}{2}}{X_{L}(1-s)}
$$

Thus, $Q c$ can be expressed as:

$$
Q_{C}=I_{S}^{2} X_{C}=\frac{4 V^{2} \sin ^{2} \frac{\delta}{2}}{x_{L}^{2}(1-s)^{2}} s x_{L}
$$

This rearranges to give:

$$
Q_{C}=\frac{2 V^{2}}{X_{L}} \frac{S}{(1-s)^{2}}(1-\cos \delta)
$$

Fig. 3.10 shows the variation in $P$ and $\mathrm{Q}_{\mathrm{C}}$, for varying values of $\mathrm{S}$ as $\sigma$ is varied.

\subsubsection{Series capacitance compensation}

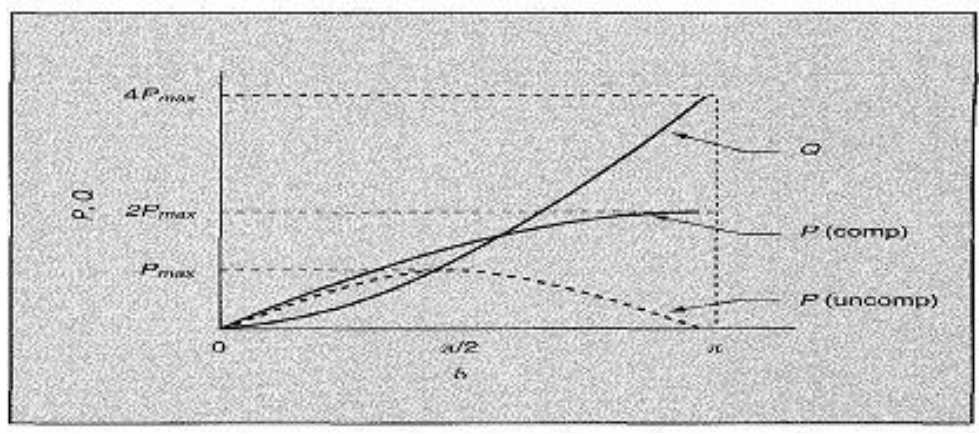

Fig. 8 shows the arrangement of series compensating the line using a mid-point capacitor to reduce the overall line reactance. This method does not improve the voltage profile but makes the line appear much shorter, electrically, than is the case. Denoting the line reactance as $\mathrm{X}_{\mathrm{L}}$, and the capacitance reactance as\&, the overall line reactance, $\mathrm{X}_{\mathrm{C}}$, becomes $\mathrm{X}_{\mathrm{C}}-\mathrm{X}_{\mathrm{L}}$ or, alternatively, $X=X_{L}(l-\mathrm{s})$, where $\mathrm{S}$ is the degree of compensation given by:

$$
s=\frac{X_{C}}{X_{L}} \quad 0 \leq s \leq 1
$$

The real power, $P$, can now be expresses as,.

$$
P=\frac{V^{2}}{X} \sin \delta=\frac{V^{2}}{X_{L}(1-s)} \sin \delta
$$

The reactive power supplied by the series capacitor is given by $Q_{C}=I^{2} X_{C}$. From the phasor diagram of Fig. 3.9, the following expression can be derived:

$$
\sin \frac{\delta}{2}=\frac{I_{s} \frac{x_{L}}{2}-I_{s} \frac{x_{c}}{2}}{V}
$$

This can be rearranged as:

$I_{s}-\frac{2 v \sin \frac{\delta}{2}}{x_{L}(1-s)}$ 
Thus, $Q c$ can be expressed as:

$$
Q_{C}=I_{s}^{2} X_{C}=\frac{4 V^{2} \sin ^{2} \frac{\delta}{2}}{X_{L}^{2}(1-s)^{2}} s X_{L}
$$

This rearranges to give:

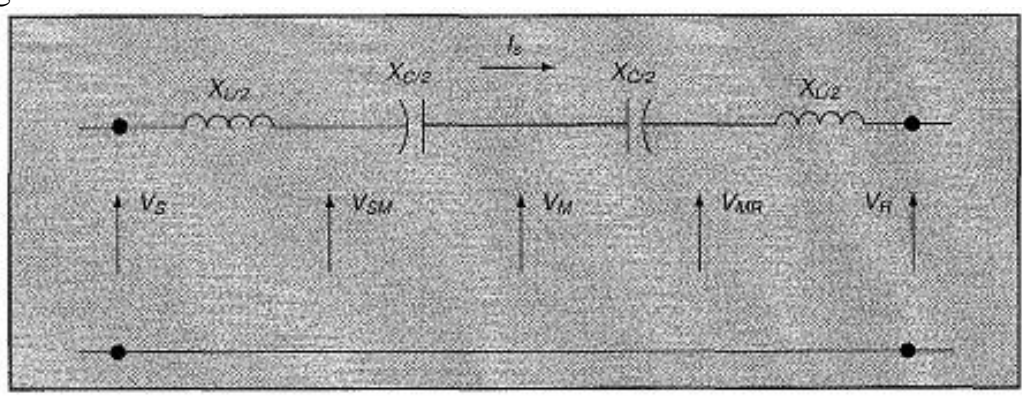

$Q_{C}=\frac{2 V^{2}}{X_{L}} \frac{s}{(1-s)^{2}}(1-\cos \delta)$

Fig. 3.10 shows the variation in $P$ and $\mathrm{Q}_{\mathrm{C}}$, for varying values of $\mathrm{S}$ as $\sigma$ is varied

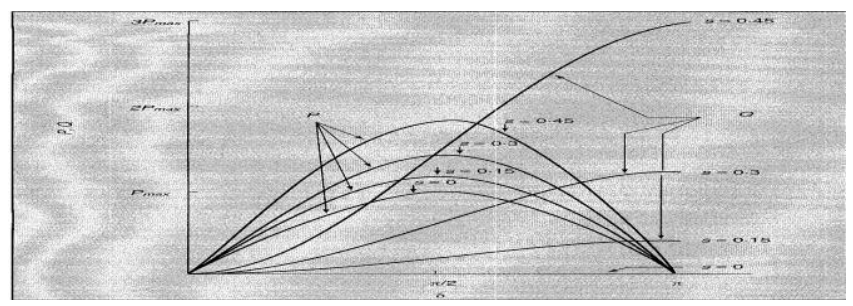

Fig3.11 Power transmission characteristic for series compensation model

\subsection{Introduction}

\section{Operating Principles And Modeling of SVC}

Static Var Compensator is an electrical device for providing fast -acting reactive power compensation on high-voltage electricity transmission network. Svc are the part of the flexible ac transmission system (FACTS) family of devices. The svc is an automated impedance matching device if the power system's reactive load is capacitive (leading), the svc will use reactors to supply VAR's to the system, bringing the system closer to unity power factor and lowering the system voltage. A similar process is carried out with an inductive (lagging) condition and capacitor bank's..

\section{Advantages}

1.SVC's include fast, precise regulation of voltage unrestricted, largely transient-free control.

2. SVC's over simple mechanically switched compensation schemes is their near instantaneous response to changes in the system voltage, for this reason they are often operated at close to their zero-point in order to maximize the reactive power correction they can rapidly provide when required.

\subsection{Introduction}

\section{Fuzzy Logic Controller}

Analytical techniques may fail to give a precise solution in a controlling process. Where as an expert or a skilled human operator, without the knowledge of their underlying dynamics of a system can control a system more successfully. So it is worth simulating the controlling strategy based upon intuition and experience can be considered a heuristic decision or rule of thumb decision. This can be possible through the Fuzzy controller.

Fuzzy set $A$ in a universe of discourse $U$ is characterized by a MF $\mu_{A}: U \rightarrow[0]$ [1] and associates with each element $\mathrm{x}$ of $\mathrm{U}$ a number $\mu_{\mathrm{A}}(\mathrm{x})$ in the interval [ $\left[\begin{array}{ll}0 & 1\end{array}\right]$ representing the degree of membership of $\mathrm{x}$ in $\mathrm{A}$. 


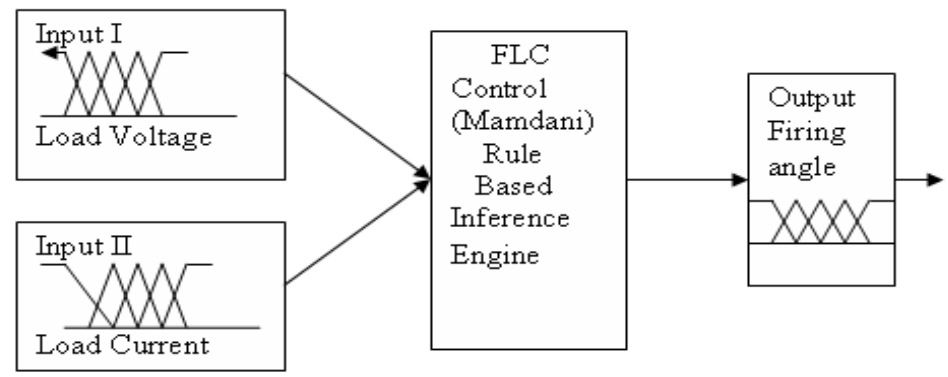

Fig 5.1 Structure of fuzzy logic controller

\subsection{Fuzzy Set Operations}

It is well known that the membership functions play an important role in fuzzy sets. Therefore it is not surprising to define fuzzy set operators based on their corresponding membership functions. Operations like AND, OR and NOT are some the most important operations of the fuzzy sets.

Suppose A and B are two fuzzy sets with membership functions $\mu_{\mathrm{A}}(\mathrm{x})$ and $\mu_{\mathrm{B}}(\mathrm{x})$ respectively then.

The AND operator or the intersection of two fuzzy sets is the membership functions of the intersection of these two fuzzy sets.

$$
\mathrm{C}=(\mathrm{A} \cap \mathrm{B}) \text {, is defined by }
$$

$\mu_{\mathrm{C}}(\mathrm{x})=\min \left\{\mu_{\mathrm{A}}(\mathrm{x}), \mu_{\mathrm{B}}(\mathrm{x})\right\}, \mathrm{x} \in \mathrm{X}$

The OR operator or the union of two fuzzy sets is the membership function of the union of these two fuzzy sets.

$$
\mathrm{D}(\mathrm{A} \cup \mathrm{B}) \text {, is defined by }
$$

$\mu_{\mathrm{C}}(\mathrm{x})=\max \left\{\mu_{\mathrm{A}}(\mathrm{x}), \mu_{\mathrm{B}}(\mathrm{x})\right\}, \mathrm{x} \in \mathrm{X}$

The NOT operator or the complement of a fuzzy set is the membership function of the complement of A is $\mathrm{A}^{1}$ is defined by

$$
\mu_{\mathrm{A}}{ }^{1}(\mathrm{x})=\left\{1-\mu_{\mathrm{A}}(\mathrm{x})\right\}, \mathrm{x} \in \mathrm{X}
$$

Fuzzy relation:

A fuzzy relation $\mathrm{R}$ from $\mathrm{a}$ and $\mathrm{b}$ can be consider as a fuzzy graph and characterized by membership function $\mu_{\mathrm{R}}$ $(\mathrm{x}, \mathrm{y})$ which satisfies the composition rules as follows.

$\mu_{\mathrm{R}}(\mathrm{x})=\max \left\{\min \left[\mu_{\mathrm{R}}(\mathrm{x}, \mathrm{y}), \mu_{\mathrm{A}}(\mathrm{x})\right]\right\}, \mathrm{x} \in \mathrm{X}$

\subsection{Fuzzy Controller Model}

Fuzzy modeling is the method of describing the characteristics of a system using fuzzy inference rules. The method has a distinguishing feature in that it can express linguistically complex non-linear system. It is however, very hand to identify the rules and tune the membership functions of the reasoning. Fuzzy Controllers are normally built with fuzzy rules. These fuzzy rules are obtained either from domain experts or by observing the people who are currently doing the control. The basic configuration of Fuzzy logic control based as shown in Fig. 5.1 consists of four main parts i.e. (i) Fuzzification, (ii) knowledge base, (iii) Inference Engine and (iv) Defuzzification.

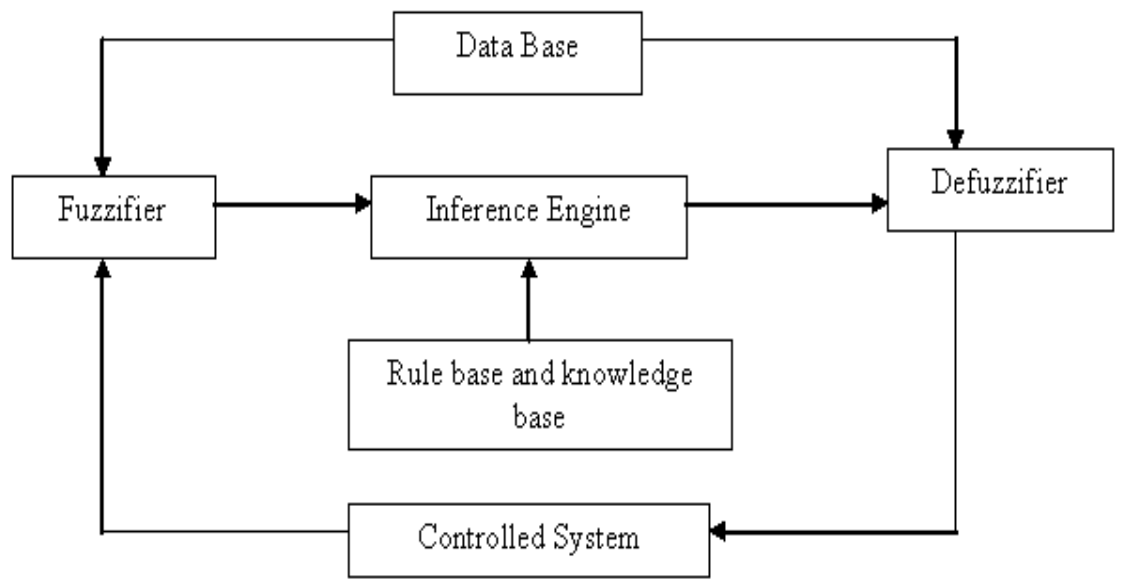

Fig. 5.2 Structure of Fuzzy Logic controller 


\subsection{Introduction}

\section{Real Time Implimentantion of SVC}

The control circuits discussed so far were discrete in nature. But now a days specially develop ICs like IC TCA 785 can replace all the discrete circuitry. This IC can be used for triggering the scr as well as traic in different application. It can be use in applications such as single phase semiconductor or full converters etc. the facilities like multiple pulse triggering, pulse width adjustment, variation in the firing angle etc. are include in addition to that the inhibit pin(pin no.6) of the IC can be used to disable the IC under fault conditions.

The IC internally generates ramp signal which is synchronized with the AC mains. It is compared with the variable DC control voltage to vary the firing angle between 0 and 180 degrees.Due to the ramp controlled firing this circuit provides a linear relationship between the control voltage and the firing angle " $\alpha$ " but the relation between the dc control

\begin{tabular}{|l|l|l|l|l|}
\hline Maximum Rating & & Lower Limit & Upper Limit & Units \\
\hline (1)Supply voltage & Vs & -0.5 & 20 & volts \\
\hline (2) Output current at pins 14\&15 & $\mathrm{I}_{\mathrm{Q}}$ & -15 & 300 & $\mathrm{~mA}$ \\
\hline (3) Inhibit voltage & $\mathrm{V}_{6}$ & -0.5 & $\mathrm{Vs}$ & volts \\
\hline (4) Control voltage & $\mathrm{V}_{11}$ & -0.5 & $\mathrm{Vs}$ & volts \\
\hline (5) Output voltage at pins 14\&15 & $\mathrm{V}_{\mathrm{Q}}$ & - & $\mathrm{Vs}$ & volts \\
\hline (6) Output current at pins 2,3,4,7 & $\mathrm{I}$ & - & 10 & $\mathrm{~mA}$ \\
\hline (7) Output current at pins 2,3,4,7 & $\mathrm{V}$ & - & $\mathrm{Vs}$ & volts \\
\hline (8) junction temperature & $\mathrm{U}$ & - & 125 & $\mathrm{C}^{0}$ \\
\hline (9) Storage temperature & $\mathrm{T}_{\mathrm{stg}}$ & -55 & 120 & $\mathrm{C}^{0}$ \\
\hline (10) Synchronizing input current & $\mathrm{Is}$ & -100 & \pm 100 & $\mu \mathrm{A}$ \\
\hline Operating range & & & & \\
\hline (1) Supply voltage & $\mathrm{Vs}$ & 8 & 18 & Volts \\
\hline (2)operating frequency & $\mathrm{f}$ & 13 & 550 & $\mathrm{~Hz}$ \\
\hline (3) Ambient temperature range & $\mathrm{T}_{\mathrm{amb}}$ & -25 & 85 & $\mathrm{C}^{0}$ \\
\hline
\end{tabular}
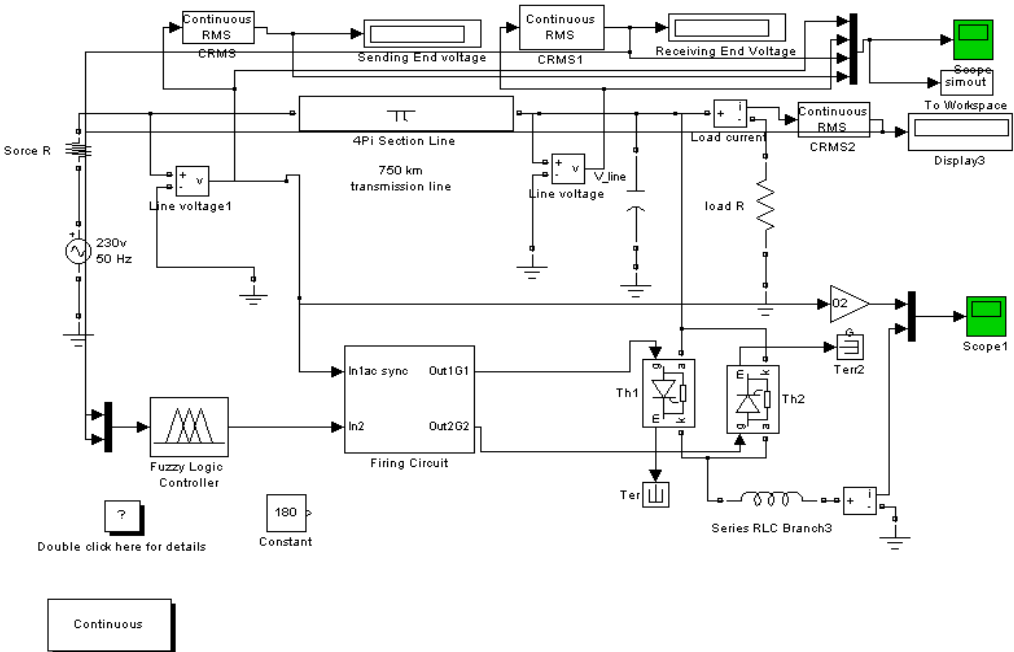

Fig 6.1 Network simulating in Matlab along with FC-TCR 


\section{Algorithm for Fuzzy Controller}

The calculation of the control action in the fuzzy algorithm is composed of the following steps.

1. Calculate Ir.

2. Convert Ir values into fuzzy variables such as PB, PM, NB, NM etc.

3. Evaluate the decision rules using the compositional rule of inference.

4. Calculate the deterministic input required to regulate the process.

5. The control rules are formulated in linguistic terms using fuzzy sets to describe the magnitude of Ir and the magnitude of firing angles $\alpha$.The ranges of Ir and $\alpha$ are quantized into a set of labels in the look-up table.

6 . The decision rules are developed heuristically for a particular control task and implemented as a set of fuzzy conditional statements.

7. Membership functions for input quantities and outputs are chosen with suitable ranges as shown in the figure .

8. The rule - box showing various values written for its control in represented in fig .

9. For testing the fuzzy outputs for the given inputs we have selected the above diagram. After verifying the results the fuzzy block is kept in the actual control loop for generating firing angles.

\section{VII.Results}

The transmission line without any compensation was not satisfying the essential condition of maintaining the voltage within the reasonable limits. The effect of increasing load was to reduce the voltage level at the load end. At light loads, the load voltage is greater than the sending end voltage as the reactive power generated is greater than absorbed.

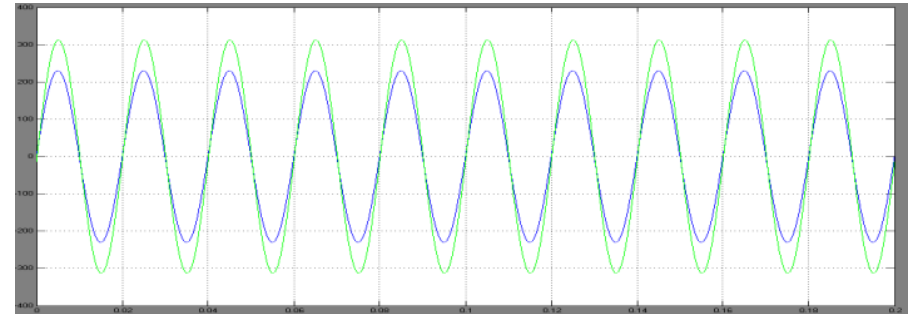

Fig 7.1 Wave-forms without compensation for light loads VR>VS as the reactive power generated is greater than absorbed

Load voltage before and after compensation

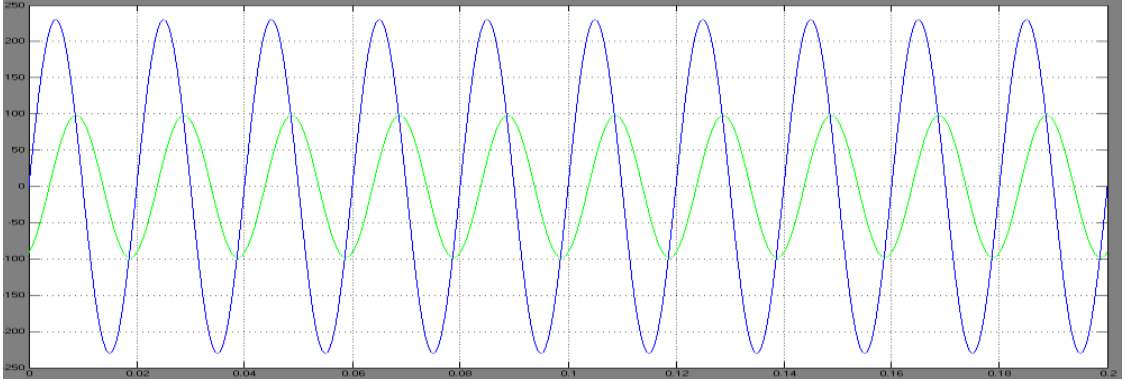

Fig 7.2 Wave-forms without compensation for heavy loads $\mathrm{VR}<\mathrm{VS}$ as the reactive power absorbed is greater than generated

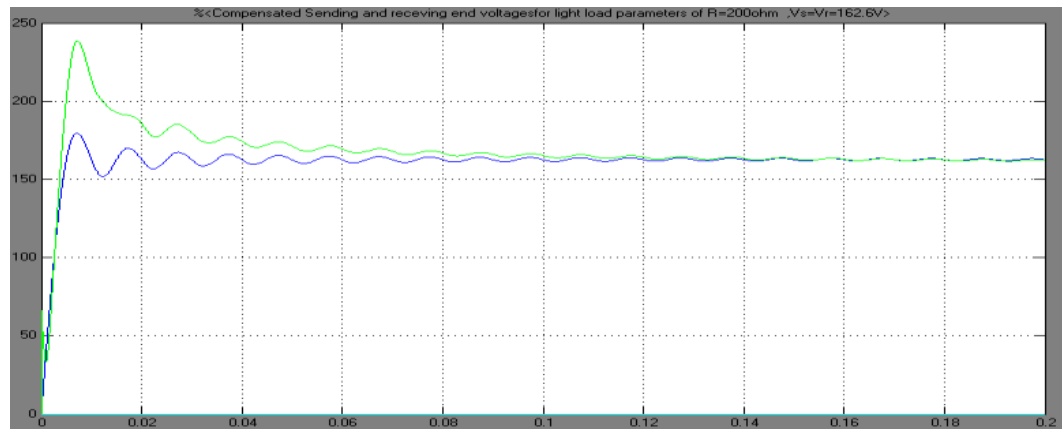

Fig 7.3 Compensated RMS voltage 


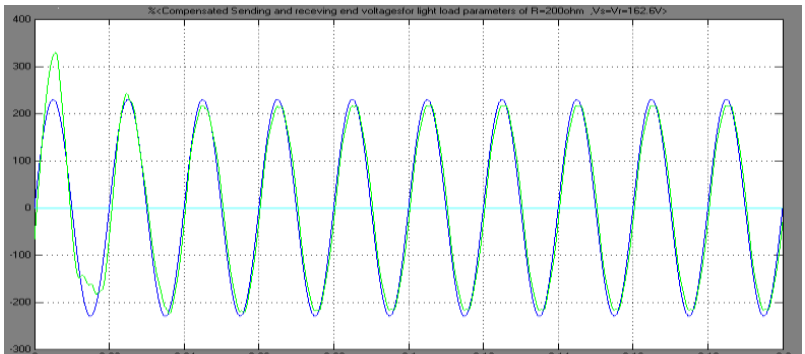

Fig 7.4 Compensated instantaneous voltage for light load

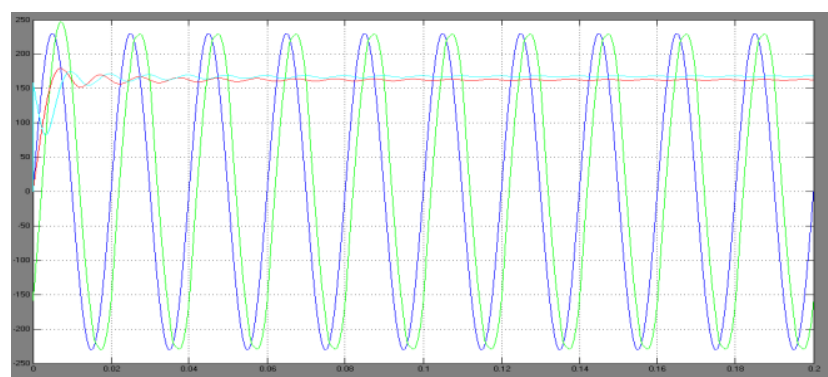

Fig 7.5 Compensated instantaneous and RMS voltage for heavy load

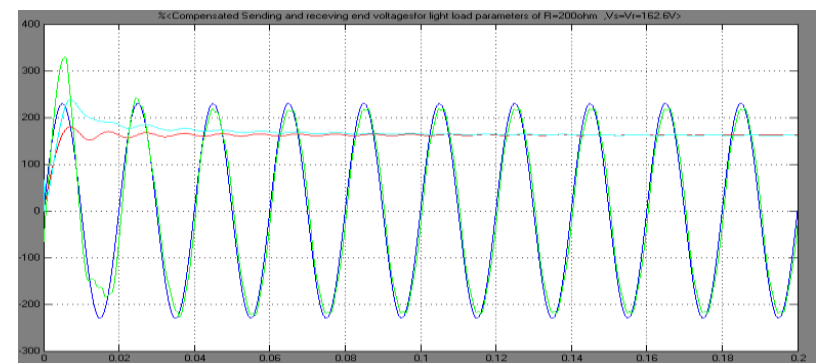

Fig 7.6 Compensated waveforms with fuzzy control

\section{Conclusions}

The Fuzzy logic block controls the firing angle circuit designed in MATLAB. The device TCR-FC is able to achieve flat voltage profile only for firing angles greater than 90 degrees. For firing angles less than 90 degrees TCR-FC is not able to control the voltage. The TCR model so designed is connected to the network to form the complete system with compensation. From the tabular forms and waveforms it is observed that the TCR-FC provides for an effective reactive power control irrespective of load variations.

It can be finally concluded that the use of TCR-FC compensating device with Fuzzy logic block serving the purpose of firing angle control is a continuous, effective and simplest way of controlling reactive power.

\section{References}

[1]. Narain. G. Hingorani, “Understanding FACTS, Concepts and Technology Of flexible AC Transmission Systems", by IEEE Press USA.

[2]. Bart Kosko, "Neural Networks and Fuzzy Systems A Dynamical Systems Approach to Machine Intelligence", Prentice-Hall of India New Delhi, June 1994.

[3]. Timothy J Ross, "Fuzzy Logic with Engineering Applications", McGraw-Hill, Inc, New York, 1997.

[4]. Laboratory Manual for Transmission line and fuzzy Trainer Kit Of Electrical Engineering Department NIT Warangal

[5]. SIM Power System User Guide Version 4 MATLAB Manual

[6]. Periodicals and Conference Proceedings:

[7]. S.M.Sadeghzadeh M. Ehsan "Improvement of Transient Stability Limit in Power System Transmission Lines Using Fuzzy Control of FACTS Devices ,IEEE Transactions on Power System Vol.13 No.3 ,August 1998

[8]. Chuen Chien Lee "Fuzzy Logic in Control Systems: Fuzzy Logic Controller". Part I and Part II. IEEE R. IEEE transactions on system, man ,and cybernetics, vol.20 March/April11990

[9]. A.M. Kulkarni, "Design of power system stabilizer for single-machine system using robust periodic output feedback controller", IEE Proceedings Part - C, Vol. 150, No. 2, pp. 211 - 216, March 2003. Technical Reports: Papers from Conference Proceedings unpublished):

[10]. U.Yolac,T.Talcinoz Dept. of Electronic Eng.Nigde 51200,Turkey "Comparison Compariiison of Fuzzy Logic and PID Controls For TCSC Using MATLAB"

[11]. Jaun Dixon ,Luis Moran, Jose Rodrfguz ,Ricardo Domke "Reactive power compensation technology state- of- art- review”(invited paper) 
[12]. Electrical Engineering Dept Pontifica Universidad Catolica De CHILE.

[13]. L. Gyugyi, "Principles and applications of static, thyristor-controlledShunt compensators," IEEE Trans. Power App. Syst., vol. PAS97, pp.1935-1945, Sept./Oct. 1978.

[14]. "Reactive power and control by thyristor circuits," IEEE Trans.Ind. Applicat., vol. IA-15, pp. 521-532, Sept./Oct. 1979.

[15]. S. E. Haque, N. H. Malik, and W. Shepherd, "Operation of a fixed Capacitor-thyristor controlled reactor (FC-TCR) power factor compensator,” IEEE Trans. Power App. Syst., vol. PAS-104, pp. 1385-1390, June 1985. 